\title{
A FORMAÇÃO DO PROFISSIONAL DE EDUCAÇÃO FÍSICA E O SISTEMA ÚNICO DE SAÚDE
}

\author{
George Saliba Manske' \\ Daniel de Oliveira²
}

\section{RESUMO}

Inserindo-se nos debates acerca da formação profissional para o campo da saúde este estudo teve como objetivo identificar o conhecimento dos estudantes de Educação Física de uma Instituição de Ensino Superior de Santa Catarina sobre a atuação deste profissional na Atenção Básica do Sistema Único de Saúde, por meio do Núcleo de Apoio à Saúde da Família. É uma pesquisa de cunho qualitativo e na produção dos dados foi utilizada uma entrevista semiestruturada. Identificou-se que os estudantes pesquisados tinham pouco ou nenhum conhecimento acerca do Sistema Único de Saúde, da Atenção Básica e dos Núcleos de Apoio à Saúde da Família, dificultando uma compreensão do fazer profissional da Educação Física nesse campo de atuação. Sugere-se que os princípios que regem o Sistema Único de Saúde, assim como, as estruturas que o compõem, sejam cada vez mais enfatizadas e reforçadas nos cursos de formação profissional em Educação Física.

Palavras-chave: Sistema Único de Saúde. Educação Física. Formação Profissional.

1 Doutor em Educação. Professor da Universidade do Vale do Itajaí (UNIVALI). São José/Santa Catarina, Brasil. E-mail: gsmanske@yahoo.com.br

2 Mestre em Saúde e Gestão do Trabalho. Universidade do Vale do Itajaí (UNIVALI). São José/Santa Catarina, Brasil. E-mail: edf.daniel@hotmail.com 


\title{
PROFESSIONAL QUALIFICATION IN PHYSICAL EDUCATION AND UNIFIED HEALTH SYSTEM
}

\begin{abstract}
The present article is part of a broader discussion on the vocational training of professionals involved in the Healthcare Field. My aim is to identify the degree of knowledge hold by students of Physical Education, from a College institution in Santa Catarina, in regard to their attainment to the Primary Care in Public Health System (SUS) through specific professional practices in the Support Center for Family Health. The nature of the present survey is qualitative, and the data was collected by means of the semi-structured interview. As a result, I observed the complete illiteracy or only partial knowledge of the functioning of Public Health System, Primary Care, Health Family Support Systems by the students, hindering, therefore, an understanding of their professional exercise in this field of activity. My theoretical intervention is the emphatic observance of the principles, which reign the Public Healthcare, as well as the institutions which comprise it, as part of the vocational training in under-graduation courses in the field of Physical Education.
\end{abstract}

Keywords: Health System. Physical Education. Professional Qualification.

\section{LA FORMACIÓN PROFESIONAL EN EDUCACIÓN FÍSICA Y LO SISTEMA ÚNICO DE SALUD}

\section{RESUMEN}

En la inserción de discusiones acerca de la formación em el area de la salud este estudio tuvo como objetivo identificar el conocimiento de los estudiantes de Educación Física de una institución de educación superior de Santa Catarina en el desempeño del profesional de la Educación Física en el Sistema de Salud, a través del centro de apoyo desalud de la Familia. Se trata de una investigación cualitativa y la producción de datos se utilizó una entrevista semiestructurada. Se identificó que los estudiantes encuestados tuvieron poco o ningún conocimiento del Sistema de Salud, Atención Primaria y los Centros de Apoyo a la Salud de la familia. Se sugiere que los principios que rigen el sistema único de salud, así como las estructuras que lo componen, se enfatizan y reforzadas en el transcurso de la formación profesional en educación física.

Palabras clave: Sistema de Salud. Educación Física. Formación Profesional. 


\section{INTRODUÇÃO}

É imprescindível na atualidade estar a par dos debates acerca da formação superior e profissional para as diferentes atuações no campo da saúde. Dentre as inúmeras profissões voltadas à saúde a Educação Física está em crescente expansão, sendo incluída na área da Saúde Pública através dos Núcleos de Apoio à Saúde da Família (NASF) desde 2008. Desse modo, há que se indagar se as formações nas Instituições de Ensino Superior (IES) vêm abordando e contribuindo para o desenvolvimento de competências e habilidades para que seus discentes tornem-se futuros profissionais em sintonia com o que se prevê e se espera no âmbito do Sistema único de Saúde (SUS), assim como, quais as percepções e conhecimentos dos discentes acerca deste campo e sobre seus papéis enquanto profissionais (FRAGA; CARVALHO; GOMES, 2013; GOMES; FRAGA; CARVALHO, 2015).

Diante deste cenário, por exemplo, a literatura nacional tem apresentado inúmeros estudos acerca da inserção e relação dos profissionais de Educação Física na Saúde Pública (PALMA, 2001; FREITAS, 2007; FRAGA; CARVALHO; GOMES, 2013). Em seu estudo Palma (2001) analisou as interpretações de profissionais de Educação Física relacionadas ao conceito de saúde, enfatizando os sentidos e significados que se constroem sobre o corpo humano desde as possibilidades de compreensão elencadas num determinado ponto de vista conceitual sobre corpo e saúde.

Por outro lado, no que se refere a trabalhos que visam identificar a compreensão de acadêmicos de Educação Física sobre seu papel na Saúde Pública, ainda se encontram poucos registros na literatura, embora alguns estudos se aproximem dessa temática. Um deles se refere à investigação de saberes e práticas enfatizadas na formação acadêmica do profissional de Educação Física com relação à saúde pública (BATTAGLION, 2003), enquanto em outro se analisou a contribuição do PET-Saúde (Programa de Educação pelo Trabalho para a Saúde) na formação acadêmica e profissional de bolsistas de um curso de Educação Física de uma universidade do Sul do Brasil (RAFAELI, 2013).

Frente ao exposto é possível indicar que são escassos os estudos que buscam compreender o que os acadêmicos de cursos superiores de Educação Física sabem sobre as diretrizes de suas práticas relacionadas à Saúde Pública, e desse modo, estudos que busquem compreender estes aspectos tornam-se relevantes. Primeiramente porque podem contribuir para o enriquecimento da literatura científica sobre o tema, bem como estimular que mais pesquisas e estudos sobre a temática sejam realizados. Em segundo lugar porque a análise do tipo de conhecimento discente acerca da Saúde Pública pode indicar os modos pelos quais ações profissionais serão delineadas, assim como, apontar quais as lacunas que precisam ser mais bem organizadas na formação futura dos novos acadêmicos que estão por ingressar. Assim, poder-se-ia sugerir que a atenção a esses aspectos - e seus possíveis ajustes - pode incidir num prática profissional mais adequada aos princípios do SUS, como por exemplo, práticas mais humanizadas e que estimulem a participação social, a promoção da saúde, o fortalecimento da integralidade e uma concepção ampliada sobre saúde (FRAGA; CARVALHO; GOMES, 2013; GOMES; FRAGA; CARVALHO, 2015). 
Foi nesse sentido que este estudo foi desenvolvido, tendo como propósito investigar o conhecimento dos estudantes de Educação Física de uma Instituição de Ensino Superior do Estado de Santa Catarina sobre o que é preconizado pelas regulamentações que regem o SUS e as Diretrizes do NASF, apontando para novas formas de como desenvolver uma formação em Educação Física com vistas ao fortalecimento da atuação deste profissional no SUS. Frente a essa intenção geral de pesquisa, organizamos o estudo a partir da seguinte questão: Quais os conhecimentos dos estudantes de Educação Física de uma Instituição de Ensino Superior de Santa Catarina sobre a atuação do profissional de Educação Física na Atenção Básica $(A B)$ por meio do Núcleo de Atenção à Saúde da Família (Nasf)?

\section{MATERIAIS E MÉTODOS}

Esta pesquisa foi realizada em uma IES de Santa Catarina, com os estudantes concluintes do Curso de Educação Física - Bacharelado. A escolha da instituição justificou-se por sua relevância social para a região onde está inserida, uma vez que ela é a responsável pela formação do maior número de profissionais de Educação Física atuantes naquela localidade, tanto na área do bacharelado (clubes, academias, escolinhas de esportes, artes marciais, etc.) quanto na área da licenciatura (Educação física escolar).

No que diz respeito à seleção dos participantes foi utilizado como critério que os mesmos necessitavam estar regularmente matriculados no último ano do curso de Bacharelado em Educação Física. A população que atendia este critério estava estimada em 35 estudantes. Inicialmente ocorreu a apresentação da proposta da pesquisa ao coordenador do referido curso e, após aceitação por parte do coordenador, seguiram os trâmites legais e éticos exigidos para a realização da pesquisa. Para tanto, foram seguidas as diretrizes e normas regulamentadoras de pesquisas envolvendo seres humanos, contidas na Resolução 466/2012 do Conselho Nacional de Saúde e suas complementares, que dispõem sobre Diretrizes e Normas Regulamentares na Pesquisa com Seres Humanos. Sendo aprovado o projeto este recebeu o parecer favorável do Comitê de Ética e Pesquisa com o seguinte número: 854.549 da data de 30/10/2014.

Após aprovação da pesquisa pelo Comitê de Ética foi feito um convite para participação voluntária dos estudantes concluintes da Instituição pesquisada. Nesse momento dez estudantes se propuseram voluntariamente a participar, sendo que destes dez, sete aceitaram participar da entrevista e três recusaram. Dos sete que aceitaram participar, todos estavam matriculados na última fase do Curso de Educação Física - Bacharelado. Para preservar a identidade dos participantes foi utilizada a letra "E", seguida de numeral ( 1 a 7) para identificar os entrevistados. O agendamento das entrevistas ocorreu de acordo com a disponibilidade de tempo dos estudantes, seguido da assinatura do Termo de Consentimento Livre Esclarecido no ato da realização das entrevistas.

Para a produção de dados junto aos estudantes foi utilizado como técnica uma entrevista semiestruturada e diário de campo para o registro dos dados. A entrevista semiestruturada é entendida como uma entrevista direcionada por um roteiro composto por 
questões abertas previamente elaboradas (BELEl, 2008). Quanto à elaboração do roteiro, este parte da vivência do pesquisador, além do que trata a literatura sobre o tema e das informações advindas do pré-teste (SCHRAIBER, 1995). Desse modo, o roteiro de entrevistas procurou atender aos objetivos geral e específicos do estudo, tendo como tópicos norteadores os seguintes: perfil dos entrevistados; formação curricular específica para a área da Saúde Pública, em especial disciplinas e estágios obrigatórios; concepção de saúde; e, por fim, estrutura e funcionamento do SUS. Com o intuito de melhor aproveitar as informações e outros elementos como pausas, entonação de voz, expressões de dúvidas contidas na entrevista, as entrevistas foram gravadas, pois assim permitiu um melhor registro dessas informações (SCHRAIBER, 1995). Vale ressaltar que foi realizado pré-teste da entrevista semiestruturada, para assegurar uma maior precisão do instrumento. Com o pré-teste, também, foi possível verificar a estrutura e a clareza do roteiro, que aconteceu por meio de uma preliminar com sujeitos que possuíam características próximas a da população alvo (BELEI, 2008).

No que se refere aos procedimentos analíticos dos dados, neste estudo foi realizada uma análise de conteúdo (BARDIN, 2011). Neste procedimento tem-se a atenção para três etapas que permeiam a construção analítica das discussões subsequentes, a saber, a fase da descrição ou preparação do material, a inferência ou dedução, e a interpretação. Ainda segundo Bardin (2011) , para o tratamento dos dados há necessidade do desmembramento do texto em unidades, ou seja, descobrir os diferentes núcleos de sentido que constituem a comunicação, e posteriormente, realizar o seu reagrupamento em classes ou categorias.

Assim, após a primeira fase de análises propusemos três subcategorias para discussão acerca de uma categoria ampla denominada 'Conhecimento insuficiente sobre SUS', a fim de atender o objetivo geral de pesquisa que foi identificar quais os conhecimentos dos estudantes de Educação Física de uma Instituição de Ensino Superior de Santa Catarina sobre a atuação do profissional de Educação Física na Atenção Básica (AB) por meio do Núcleo de Atenção à Saúde da Família (Nasf). As três subcategorias vinculadas a grande categoria acima descrita estão assim denominadas: 'Atenção Básica', 'NASF' e 'Apoio Matricial'. Foram destacadas nas falas as expressões mais presentes dos entrevistados com relação às categorias identificadas, a fim de discutir e analisar estes excertos com a literatura aqui relacionada. Na discussão dos resultados, a partir do que foi interpretado das entrevistas bem como da fundamentação teórica, foram transcritos trechos das entrevistas que corroboraram com as interpretações.

\section{RESULTADOS E DISCUSSÃO}

\section{Conhecimento Insuficiente sobre SUS}

O Sistema Único de Saúde (SUS) é entendido pelo Ministério da Saúde (MS) como uma formulação política e organizacional dos serviços e ações relacionadas à saúde, estabelecido a partir da Constituição Federal de 1988. O SUS é considerado único, pois 
abrange em igualdade de princípios todo o território nacional nas três esferas autônomas de governo (união, estado e municípios), e também é visto como sistema, pois abrange um conjunto de unidades, de serviços e ações com a finalidade de promoção, proteção e recuperação da saúde. Seus princípios são a Universalidade, que prevê que todos os cidadãos têm direito de acesso a todos os serviços prestados; a Equidade, princípio que considera todo cidadão de maneira igual, com atendimento de acordo com suas necessidades e de acordo com as limitações do próprio sistema; e a Integralidade, onde se insere a prática do serviço que considera o ser humano a partir de sua concepção biopsicossocial, prevendo ações de promoção, proteção e recuperação da saúde, apresentando assistência integral aos usuários (MINISTÉRIO DA SAÚDE, 1990).

Ao abordar questões referentes ao SUS pudemos notar que as respostas dos entrevistados tratavam muito mais da falta de experiência ou das experiências que estes já tiveram como usuários do sistema do que propriamente o conhecimento que eles tinham ou não sobre o SUS. Por exemplo, o E1 fez a seguinte afirmação: "Então, vou falar do que eu conheci, do que eu vivi. Não... Dentro do que é o sistema, não posso falar, por que também, não tenho o conhecimento". Esta fala se assemelha a do E7, que reitera que entende "que a gente tenha que saber mais sobre e aproveitar bastante os postos de saúde".

Podemos perceber a partir das falas do E1 e E7 indícios sobre seu pouco conhecimento sobre o SUS. Aliás, como futuros profissionais da área da saúde, seus conhecimentos sobre o SUS parecem estar fragilizados, sendo possível indagar se sua formação acadêmica possa ter oportunizado suficientemente conhecimento sobre o sistema brasileiro de Saúde Pública. Pasquim (2010), que em seu estudo verificou as Diretrizes Curriculares Nacionais para os cursos de graduação em educação física, constatou que segundo estas diretrizes o profissional formado deveria ser responsável pela prevenção, promoção, proteção e reabilitação da saúde, e destaca que essa responsabilidade aparece diversas vezes neste documento. No entanto, é possível inferir a partir das considerações do referido autor que a inserção deste campo de atuação nas diretrizes de formação em Educação Física tem cumprido muito mais o papel de reserva de mercado do que de orientação à formação específica para a Saúde Pública, sendo que essa inserção nas diretrizes não impõe nenhuma alteração na formação acadêmica.

De acordo com a Lei 8.080/90, que regulamenta o funcionamento do SUS, são alguns de seus objetivos a identificação e divulgação dos fatores condicionantes e determinantes da saúde, formulação de políticas de saúde, assistência às pessoas por intermédio de ações de promoção, proteção e recuperação da saúde. Além do mais, deve procurar a execução de ações de vigilância sanitária, de vigilância epidemiológica, de saúde do trabaIhador e de assistência integral, de assistência terapêutica integral - inclusive farmacêutica, a ordenação da formação de recursos humanos na área da saúde, vigilância nutricional e alimentar, a fiscalização de serviços, produtos e substâncias de interesse para a saúde (MINISTÉRIO DA SAÚDE, 1990). Sendo assim, o SUS se mostra importante no sentido de ser entendido como uma política social que caminha contra os atuais processos políticos, ideológicos e econômicos de exclusão social (GOUVEIA; PALMA, 1999). Estes pressupostos nos remetem a um trecho da fala do E1, que apesar de afirmar que não pode falar sobre 
o sistema por não ter conhecimento, mostrou e apontou alguns pontos em que o sistema em sua opinião ainda deveria melhorar. Segundo o E1:

\begin{abstract}
O SUS ele tem muita coisa pra ser melhorada, especificamente, pessoas que trabalham com o SUS. Tem muita gente boa, mas tem muito que não quer tá lá. Não sei se por financeiro ou é hábito: "ah to no SUS, eu vou te atender mal". Muito pelo contrário, acho que as pessoas que vão já são carentes, já precisam de um apoio específico. E muitas vezes chegam lá e o atendimento é demorado. Não tem explicação do porquê vai ser, do porquê da fila...da demora, . E tem muita coisa pra ser melhorada dentro do SUS, partindo primeiro das pessoas. De repente fazer uma reformulação, ou algum trabalho. Dizer assim: "oh as pessoas são todas iguais, atendam bem". Mas em contrapartida tem alguns...alguns... atendimentos que são bons. Ah... como exemplo os postos de saúde, eles são bem atendidos né, então tem... tem os dois lado. Como em tudo. (E1)
\end{abstract}

Corroborando com E1, vale ressaltar que os serviços públicos sofrem frequentemente questionamentos com relação a sua eficiência, pois se questiona a capacidade de produção e de atendimento aos desejos das populações beneficiadas pelos serviços prestados. Normalmente a demora e a burocracia são características atribuídas ao setor público, o que acaba fazendo com que a população se torne descrente com relação à capacidade das entidades públicas cumprirem o seu papel (POLITELO; RIGO; HEIN, 2015).

O entrevistado 6 reforçou a situação do mau atendimento no SUS, falando sobre sua própria vivência, relatando um atendimento que experimentou, e que em sua opinião não foi positivo. Quando questionado sobre esse tema explanou o seguinte:

Olha o que eu tenho pra falar do SUS é que eu não gosto do atendimento, até por que já precisei ser atendido até no pronto socorro e o que eles fazem normalmente quando a gente chega lá? Às vezes eles nem sabem se a gente tem alguma infecção ou qual o problema. E já aplicam medicamentos para dor. Então, já aconteceu comigo, e isso não resolve nada. Acho que deveria ter um atendimento, com profissionais mais específicos para cada área. [...] Eu sou contra assim. Não acho um bom atendimento (E6).

Nesse ínterim, é possível indicar que os usuários do SUS tem uma preferência histórica por pronto atendimento e hospitais ao invés da Atenção Básica (AB), recurso que vem sendo enfatizado na política pública de saúde como a porta de entrada para o SUS (DE OLIVEIRA; MATTOS; SOUZA, 2009). O estudo realizado por De Oliveira, Mattos e Souza (2009) corrobora com a fala de E1 e E6, visto que uma boa parte dos entrevistados para este estudo relatou dificuldades de acesso, o mau atendimento e a baixa resolubilidade do sistema de saúde, sendo que caso não haja problemas no atendimento tal fenômeno é atribuído à sorte e ao acaso.

Vale ressaltar que em 2003 o Ministério da Saúde lançou a Política Nacional de Humanização $(\mathrm{PNH})$, um documento que busca pôr em prática os princípios do SUS, estimulando a comunicação entre gestores, trabalhadores e usuários do sistema com o intuito de enfrentar as relações de poder que podem acarretar em práticas desumanizadas 
que limitam a autonomia e corresponsabilidade entre profissionais da saúde e usuários do SUS (MINISTÉRIO DA SAÚDE, 2003). Nesse sentido, percebemos que desde 2003 há uma preocupação por parte do Ministério da Saúde em melhorar as práticas de atendimento, tornando-as mais humanizadas, porém, as falas dos entrevistados mostram que isso ainda precisa ser fortalecido dentro do Sistema. Um dos princípios da PNH é o acolhimento, que seria o ato de reconhecer que o outro traz uma necessidade de saúde legítima e única. O acolhimento deve acontecer de maneira coletiva com o fim de construir confiança, vínculo e compromisso entre equipes e serviços, trabalhadores, equipes e usuários em sua rede socioafetiva (MINISTÉRIO DA SAÚDE, 2003). E1 e E6 apontam que o princípio do acolhimento, levando em conta a necessidade de saúde dos usuários como real e singular, não foi estabelecido em suas vivências e percepções com o SUS.

O E2 apesar de não afirmar que não tem conhecimento sobre o SUS, em sua fala deixa claro que não está preparado para trabalhar no sistema, como podemos perceber a seguir:

Eu falo isso pela minha grade que eu tive na faculdade sabe. Eu falo isso por isso.
Eu olhando assim, eu num posto de saúde, acho que ia ficar perdida, porque eu não
saberia o que fazer, de que maneira, qual área que eu iria estar lá dentro. [...] Então,
aí é que tá, eu não saberia que área que eu iria atuar lá. Ah não ser que seria como
auxiliar, auxiliar eu sou totalmente a favor. Agora dar alguma coisa importante pra
fazer? Por que assim ó, na minha concepção o profissional de educação física num
bacharel, ele saí da faculdade pra ir pra uma escola de futsal, academia, é personal,
essas coisas assim. Se ele quer trabalhar mais na área da saúde, acho que ele teria
que ter uma especialização a mais. (E2)

A aprendizagem significativa, que parte da experiência e da observação crítica da realidade, gera sentimentos que por vezes produzem incômodos, o que remete a mudanças e transformações. A situação real é a referência da aprendizagem, ou seja, por meio da problematização da situação real se constrói o conhecimento. Sendo assim, o conhecimento se produz de forma ativa, resultando do movimento das sensações e desconfortos. A formação profissional para o trabalho em saúde é fundamental para a reorientação do sistema de saúde. Tanto a formação quanto a qualificação dos profissionais de saúde para o trabalho no SUS tem ganhado ênfase como estratégia frente às mudanças que ocorreram no setor saúde (ESPERIDIÃO; LEAL; FONTOURA, 2012). Tendo tal cenário como horizonte para ampliação da formação específica para a área da saúde, de modo a preencher lacunas na formação nesta área, recentemente três Grupos de Pesquisa no Brasil, provenientes de três Universidades, a saber, Universidade Federal do Rio Grande do Sul (UFRGS), Universidade de São Paulo (USP) e Universidade Federal do Espírito Santo (UFES), se organizaram num projeto de investigação e formação de professores e profissionais de Educação Física para a saúde pública e coletiva. Este coletivo de pesquisadores concorreu a um edital de pesquisa da Coordenação de Aperfeiçoamento de Pessoal de Nível Superior (Capes), em parceria com a Secretaria de Gestão do Trabalho e da Educação na Saúde do Ministério da Saúde em 2010 e foram contemplados com recursos para o desenvolvimento de um 
projeto interinstitucional denominado "Políticas de formação em educação física e saúde coletiva: atividade física/práticas corporais no SUS" (FRAGA; CARVALHO; GOMES, 2012).

Tal projeto gerou seminários de discussão e a produção direta de dois livros, um deles intitulado "As práticas corporais no campo da saúde" (FRAGA; CARVALHO; GOMES, 2013) e "Práticas corporais no campo da saúde: uma política em formação" (GOMES; FRAGA; CARVALHO, 2015), além de ter contribuído diretamente para outro livro, na medida em que foi organizado por alunos de pós-graduação vinculados a este projeto, a saber, "Educação Física e Saúde Coletiva - cenários, experiências e artefatos culturais" (WACHS; ALMEIDA; BRANDÃO, 2016). É possível inferir, a partir do exposto, que as lacunas referentes à formação específica para o campo da saúde tem se tornado um tema de amplo debate e investimentos teóricos e metodológicos, na direção de uma politica de formação qualificada para as áreas da Saúde Pública e Coletiva.

Ainda sobre o comentário do entrevistado 2 que tensiona às políticas de formação na Educação Física para a área da Saúde Pública, é possível reiterar que as discussões sobre a formação profissional tem hoje destaque na agenda de debates sobre políticas de educação e saúde, feitos com o intuito de melhorar a qualidade do serviço prestado a população. Um exemplo disso seria a Residência Multiprofissional em Saúde (MINISTÉRIO DA EDUCAÇÃO, 2012), que é uma ação que visa reformular a prestação dos serviços, a formação profissional e as práticas de ensino, que resultariam em novas ações de atendimento junto com as entidades formadoras e o SUS.

Ainda acerca dos conhecimentos sobre o SUS por parte dos entrevistados o E3 reforça que também não sabe como funciona o sistema e traz um olhar específico desde a administração, especificamente para os recursos financeiros, quando relata que

não sei como funciona. Se vem dinheiro ou é mal administrado, ou se não vem, não tenho esse conhecimento pra tá falando. Sei que há muitas pessoas que também gostam de reclamar, né. Às vezes nem tem o porquê, mas reclamam. Sempre tão reclamando de tudo. Então é isso (E3).

É possível registrar que a gestão do SUS acontece de forma descentralizada, quando os gestores de saúde, em posse dos recursos financeiros que vem da União, tem liberdade de usá-los de maneira que atenda as exigências e demanda da realidade local, obviamente, cabendo seu uso somente ao setor saúde (COSTA, 2012). Quanto à fiscalização desses recursos, já que o E3 citou em sua fala a possibilidade de má administração, cabe destacar que compete aos conselhos estaduais e municipais de acordo com a lei 8.142/1990, c/c $\S 3^{\circ}$ do art. 77 do Ato das Disposições Constitucionais Transitórias (ADCT) questões referentes à fiscalização dos recursos, sendo que a apreciação das contas cabe aos Tribunais Estaduais ou Municipais de Contas, exceto em caso de Auditoria do Ministério da Saúde (COSTA, 2012).

Mesmo que até o momento só tenhamos destacado excertos de entrevistas que indicam uma falta de conhecimento específico sobre o SUS, é possível relatar também alguns excertos que apresentam alguns indícios de conhecimento sobre o sistema nacional 
de saúde. O entrevistado 5, por exemplo, referiu que já teve uma experiência profissional no SUS, pois trabalhava antes mesmo de sua formação em educação física na parte de agendamento de consultas numa unidade de saúde. Este entrevistado chama atenção para o tempo de demora na realização de um atendimento. Nesse ínterim, E5 enfatiza:

\begin{abstract}
Olha, é difícil isso né, por que muitas pessoas que precisavam mesmo, elas ficavam para trás, e a fila crescia, e isso era muito complicado, por que quando a gente tava chamando pessoal de novembro [...] a gente tava em março do outro ano. E às vezes não dava tempo para pessoa esperar, ela tinha que pagar particular, e não são todos, geralmente quem procura o SUS, não tem condições de pagar uma consulta particular ou um exame particular. Então, a pessoa tinha que se sacrificar para pagar um particular por que não tinha como esperar mesmo (E5).
\end{abstract}

A porta de entrada da população para o atendimento de saúde deve ser por meio do nível primário de atenção, que por sua vez está qualificado para atender e resolver os principais problemas de saúde, sendo que os casos de maior complexidade devem ser encaminhados para os demais níveis de assistência. Os atendimentos e serviços, organizados dessa forma (hierarquizada e regionalizada), deveriam permitir o atendimento dos problemas de saúde dos usuários de uma área delimitada, o que favoreceria ações de vigilância, controle de vetores, educação em saúde, além das ações de atenção ambulatorial e hospitalar em todos os níveis de complexidade (VIEGAS; PENNA, 2013).

Viegas e Penna (2013) apresentam relatos de usuários que também comentaram sobre o demorado tempo de espera para ser atendido em uma consulta. O excerto abaixo remete diretamente aos achados nessa pesquisa:

\begin{abstract}
A consulta de ginecologia, ela é realizada aqui no município. Então, ou o enfermeiro ou o médico ele dá um encaminhamento pra vir aqui na Unidade marcar. Se for o caso de precisar de uma cirurgia, de um tratamento mais complexo que tiver que ir pra fora, eles encaminham e depois a Secretaria de Saúde se encarrega de marcar, aí dificulta um pouco por causa da cota de consultas que está pouca. E aí demora algum tempo... Então é urgência, você tem que se virar, porque dentro da Secretaria de Saúde urgência não é urgência, demoram bastante alguns casos, tem outros que não, que são mais rápidos. Mas, por exemplo, neurologia, não está tendo atendimento suficiente para todo o município que a cota lá no CISAJE está baixa (VIEGAS; PENNA, 2013, p. 188).
\end{abstract}

Em um estudo em que avaliaram o acesso ao SUS a partir da percepção dos usuários, Schwartz et al (2010) registraram relatos por parte da maioria dos pesquisados de que a espera por consultas demora no máximo um mês. Três participantes relataram que as consultas podem demorar mais de dois meses e associaram isso com especialidades, uma vez que a marcação dessas consultas era feita na unidade de saúde da família, mas o atendimento acontecia em outro local, o que causava certa confusão caso o usuário não fosse informado (SCHWARTZ et al, 2010). Tais registros corroboram com o tópico referente ao atendimento e modos de agendamento na $A B$ do SUS explicitado nas falas dos entrevistados para este estudo. 
Frente ao exposto, é possível inferir que há uma falta de conhecimento sobre o SUS por parte dos entrevistados, e que isso gera, consequentemente, dificuldades de compreensão acerca dos elementos que compõem o SUS, tais como a Atenção Básica, o NASF e o Apoio Matricial. No entanto, é possível destacar a precoce inserção da Educação Física no SUS (apenas em 2008, nos NASFs) como um fator que ainda acarreta um desconhecimento do fazer profissional nessa área, incluindo aqui reorganizações curriculares para tal, e a ampliação das discussões, produções e proposições como tentativa para uma formação em Educação Física com vistas à área da Saúde Pública.

\section{Atenção Básica}

A Atenção Básica (AB), que é entendida como o contato preferencial dos usuários com o SUS, tem como norte os princípios da universalidade, da acessibilidade, do cuidado, do vínculo e continuidade, da integralidade, da responsabilização, da humanização, da equidade e da participação social (MINISTÉRIO DA SAÚDE, 2006). Este foi um tema de bastante relevância nas conversas com os entrevistados, embora tenha havido também falta de conhecimento e divergências sobre este conceito.

Quando perguntado sobre o que seria $A B$ no sistema nacional de saúde o E1 relatou que "básico para mim é o mínimo. Então em algumas situações o básico se tem. Mas não é o necessário, precisa um pouco mais. $A B$ eu acho que é de certa forma, eles querem dar alguma prioridade, facilitando as coisas pro povo mais humilde, sabe" (E1).

Podemos perceber através da fala de $\mathrm{E} 1$ que para ele a $\mathrm{AB}$ está relacionada com o cuidado mínimo e prioridade para pessoas humildes, divergindo do conceito dado pela Política Nacional de Atenção Básica (PNAB). Em um estudo que buscou analisar a formação acadêmica do profissional de Fisioterapia Silva e Da Ros (2007) constataram que a relação entre SUS e pessoas de baixa renda foi mais frequente do que os próprios autores esperavam, sendo citado pelos professores, alunos, vice coordenador do curso e até profissionais da saúde que participaram do estudo, corroborando com a fala de E1 que cita como $A B$ como um serviço que facilita as coisas para as pessoas mais humildes.

Além de divergências sobre o que seria $A B$ frente à $P N A B$, também constatamos total falta de conhecimento sobre este termo a partir das falas dos entrevistados. O E4, por exemplo, assim respondeu quando questionado: "Essa palavra também não tenho muito conhecimento, à exposição dela" (E4). Pela fala de E4, podemos perceber que o conhecimento sobre $A B$ pode ter sido insuficiente na sua formação acadêmica, pois como futuro profissional da área da saúde com possiblidade de trabalhar dentro do SUS, seria relevante que tivesse esse conhecimento, já que a $A B$ tem prioridade na agenda de formação, pois é o eixo estruturante do SUS, sendo destacado na elaboração de políticas públicas, principalmente nos desafios referentes à ampliação do acesso e melhoria da qualidade de resolutividade das ações na AB (MINISTÉRIO DA SAÚDE, 2009).

Além do mais, aqueles que procuraram responder aos questionamentos sobre AB foram marcados por muitas dúvidas em suas respostas. Quando E2 deu um caráter 
de pergunta à sua reposta procurava muito mais compreender do que se tratava $a \mathrm{AB}$ ao invés de responder ao questionamento a ele realizado. E2 teceu da seguinte maneira sua resposta: "Eu acho que seria mais isso. De todas as formas né, consultas, medicamentos. Eu acho que seria mais voltado a isso né?" (E2). Pela fala do entrevistado 2 percebemos sinais de dúvidas com relação ao conhecimento e vivência prática sobre AB. A aprendizagem através da $A B$ vai na contramão do sistema de ensino tradicional, pois o aprendizado deveria se dar diretamente na prática, na medida em que mostra-se como um cenário favorável à aprendizagem, já que nesse caso o estudante estaria imerso na realidade de grande parte da população brasileira. Nesse caso o estudante teria a oportunidade de vivenciar o processo de Clínica Ampliada, com ações tanto voltadas para prevenção de doenças como para a promoção da saúde, bem como para o acolhimento e a avaliação da vulnerabilidade das pessoas. Diferente dos estágios, esse tipo de educação envolve o estudante junto à comunidade, promovendo reflexões quem embasam a aprendizagem (FERREIRA; FIORINI; CRIVELARO, 2010).

Ações de formação em Educação Física referentes ao processo da Clínica Ampliada têm sido feitas em alguns estudos no Brasil. Mendes e Carvalho (2016) relatam a atuação do profissional de Educação Física a partir da Clínica Ampliada, tendo as práticas corporais e as atividades físicas como ferramentas de atuação do fazer profissional da Educação Física na área da Saúde Pública, e a maneira pela qual tal processo acaba por criar redes de sociabilidade entre os usuários, aproximando estas ações aos princípios do SUS.

O entrevistado 3, traz novamente a ideia de AB com o cuidado mínimo e também reforça a ideia de que não tem conhecimento suficiente para poder explanar sobre $A B$ :

Assim né, pelos dois termos, atenção básica é tu dar o mínimo de atenção. Sei lá, para uma pessoa, ou alguém que tá precisando. Ou né, tu vai... Eu acho que é isso. Mesmo que não tá precisando tu dar uma atenção básica, não sei se é com relação à saúde ou de alguma coisa nesse sentido. Eu não sei qual é o foco né. (E3)

Através do texto da Política Nacional de Atenção Básica, podemos perceber que AB ultrapassa o conceito de cuidado mínimo. O texto fala que $A B$ considera o sujeito em sua singularidade, na complexidade, na integralidade, na inserção sociocultural e busca a promoção da saúde, bem como, a prevenção e o tratamento de doenças, diminuição de danos que por sua vez comprometem o modo de vida saudável (MINISTÉRIO DA SAÚDE, 2006). Frente ao exposto, entendemos que o conhecimento sobre $A B$ encontra-se bastante limitado, sendo realizado fundamentalmente pela ideia de senso comum que a união dos termos 'atenção' e 'básica' pode sugerir, indo muitas vezes de encontro ao que é preconizado pelas políticas de saúde vigentes sobre o Núcleo de Apoio à Saúde da Família (NASF)

O Núcleo de Apoio a Saúde de Família, foi outro tema de importância para esse estudo, pois seria especificamente dentro do SUS e da AB este o espaço em que o profissional de Educação Física poderia exercer suas atividades como profissional da Saúde Pública. A criação do NASF se deu através do seguinte contexto: 


\begin{abstract}
O Ministério da Saúde criou os Núcleos de Apoio à Saúde da Família (NASF), mediante a Portaria GM no 154, de 24 de janeiro de 2008, republicada em 4 de março de 2008. O principal objetivo foi o de apoiar a inserção da Estratégia de Saúde da Família na rede de serviços, além de ampliar a abrangência e o escopo das ações da Atenção Básica, e aumentar a resolutividade dela, reforçando os processos de territorialização e regionalização em saúde (MINISTÉRIO DA SAÚDE, 2009).
\end{abstract}

No momento em que os entrevistados foram questionados sobre o NASF as respostas assinalaram sinais de dúvida e incerteza, sugerindo que o conhecimento sobre NASF é insuficiente, especialmente se considerarmos que são futuros profissionais de Educação Física que podem estar atuando em equipes interdisciplinares. Vejamos o que fala E2:

É um apoio à saúde. E acho que um [...] um apoio assim [...] com programas decerto de prevenção à saúde, pras famílias. Não aquela coisa que a mulherada vai lá na casa das pessoas fazer, aquelas visitinhas, não é isso? [se referindo às vistas domiciliares das Agentes Comunitárias de Saúde]Ué de repente seja isso, um programa para prevenir algumas doenças de repente. Que é onde os postinhos de saúde fazem, não é isso, será? (E2)

Comparando a fala de E2 com o que é preconizado pelo Ministério da Saúde, podemos perceber que seu trabalho transcende a ideia de prevenção e visitas domiciliares. Afinal, o NASF surge com o intuito de apoiar as equipes de saúde da família, através da interdisciplinaridade, pois sua equipe é formada por profissionais com diferentes conhecimentos da área da saúde (MINISTÉRIO DA SAÚDE, 2014). Sua metodologia de trabaIho consiste na ferramenta do Apoio Matricial, e pode ocorrer de duas formas, a saber, clinico-assistencial e técnico-pedagógica. A dimensão clínico-assistencial está relacionada com a clínica propriamente dita, trabalhando diretamente com os usuários. Já a dimensão técnico-pedagógica trabalha em caráter educativo com a própria equipe de saúde da família, sendo que as Diretrizes do NASF ainda reforçam que essas duas dimensões devem trabalhar simultaneamente em qualquer momento (MINISTÉRIO DA SAÚDE, 2009; 2014). Com relação à participação de $\mathrm{E} 7$, o entrevistado sinalizou sobre a criação do NASF e sugeriu algo de seu funcionamento, ainda que tenha também mostrado incerteza afirmando que ouviu falar em NASF ainda na faculdade. O E7 afirma que:

eu já ouvi também, mas acho que foi no período de faculdade que houve essa mudança aí, que outra coisa aí, apoio a saúde familiar, daí mudou para NASF, nesse período aí, deve fazer uns 2 ou 3 anos. Ou mais, mas foi no período de faculdade que eu ouvi isso aí. E NASF, foi nesse período que eu ouvi falar, não sei designar bem a amplitude desse plano né, tudo que ele engloba né. Sei que é da saúde da família, mas não sei tudo que ele engloba. (E7)

Embora tenha havido mudanças recentes acerca do NASF, é importante frisar que os acadêmicos demonstraram já ter ouvido sobre esta ferramenta da $A B$, embora não consigam precisar sobre suas características e funcionamento. Aliás, nos pareceu que o 
NASF foi um tema em que houve um pouco mais de familiaridade para os entrevistados. E1, por exemplo, destaca que compreende o NASF como uma ação "de grande importância, pois é um atendimento mais domiciliar, é uma forma de tu tá levando benefícios para pessoas carentes que não podem tá, e tá diminuindo filas né [...]" (E1). A fala de E1 corrobora com o que é colocado pelas Diretrizes do NASF levando em consideração o atendimento domiciliar, porém, vale ressaltar que o SUS é universal, e garantido por lei para atendimento a toda população brasileira, e não somente a pessoas carentes. E, aliás, o atendimento domiciliar é apenas uma das possibilidades de estratégias de intervenção.

Tendo como base uma equipe composta por profissionais de diferentes áreas do conhecimento, atuando em conjunto com equipes da saúde da família, apoiando a inserção da Estratégia Saúde da Família (ESF) na Atenção Básica (AB), o NASF aparece composto por nove áreas estratégicas para atuação, sendo elas: saúde da criança/do adolescente e do jovem; saúde mental; reabilitação/saúde integral da pessoa idosa; alimentação e nutrição; serviço social; saúde da mulher; assistência farmacêutica; atividade física/práticas corporais; práticas integrativas e complementares (MINISTÉRIO DA SAÚDE, 2009; 2014).

Por fim, ressaltamos a importância do profissional e futuro profissional de Educação Física compreender o NASF, especialmente pelo campo de atuação que se vislumbra. Desse modo, narrativas como "Sim, eu já escutei. Tinha uma colega de sala que trabalha ou trabalhava no NASF, e ela chegou a comentar com a gente, mas eu não me recordo o que seria (E5)", ou ainda, "Eu já ouvi falar, mas não sei o que é exatamente. Já ouvi falar meio por cima, mas não sei falar o que é ao certo (E6)", acabam por ir de encontro as possíveis atuações dos profissionais de educação física.

No que se refere à atuação do Profissional de Educação Física no NASF é possível indicar que este tem um papel central na proposição de práticas corporais e atividades físicas nos Núcleos de Apoio a Saúde da Família (MINISTÉRIO DA SAÚDE, 2014). No âmbito do trabalho em equipe pensando na Estratégia de Saúde da Família recomenda-se ao profissional de Educação Física que favoreça em seu trabalho a abordagem da diversidade das manifestações da cultura corporal, fugindo de conteúdos técnicos da Educação Física, não dando ênfase somente à prática de exercícios físicos atrelados a antropometria e rendimento. Sendo assim, pode estar planejando junto com os demais profissionais atividades que envolvam jogos de mesa como dominó e xadrez, danças folclóricas, bem como, danças que estão em popularidade e que promovam um processo de formação crítica do sujeito, da família ou pessoas de referência na comunidade. Vale ressaltar que o Profissional de Educação Física deve estar pronto para lidar com algumas dificuldades e barreiras, como a grande urbanização das cidades e a falta de espaços públicos para a prática do lazer, a dificuldade de acesso a parques e praças pelos mais diversos motivos, como falta de tempo, recursos financeiros, entre outros (FERREIRA; FIORINI; CRIVELARO, 2010).

Nesse ínterim, ressaltamos a necessidade de se ampliar conceitos que considerem o corpo e o sujeito de maneira integral, incluindo sua afetividade e subjetividade, tornando necessária uma atuação profissional no NASF para que que consiga compreender a saúde a partir de um ponto de vista integral do sujeito (CARVALHO, 2006; CUTOLO; CESA, 2003). 


\title{
Apoio Matricial
}

O Apoio Matricial é tomado como uma ferramenta de trabalho na $A B$, pois afinal seria a metodologia de trabalho do NASF que tem como intuito de fortalecer a Estratégia da Saúde da Família. O apoio matricial se apresenta em dois formatos de trabalho no âmbito do NASF, como clínico-assistencial e também técnico-pedagógica. A dimensão clínico-assistencial é aquela que vai produzir ação clínica direta com os usuários, e a ação técnico-pedagógica vai produzir ação de apoio educativo com e para a equipe (Educação Permanente) (MINISTÉRIO DA SAÚDE, 20014).

As equipes de NASF deverão atuar junto às equipes de Saúde da Família, fortalecendo a Integralidade das ações, mas não somente enfatizando esse aspecto, pois também devem buscar a resolutividade, a qualidade do cuidado, a promoção da saúde, bem como, acompanhar e monitorar essas diversas ações. Outro princípio norteador do NASF é a interdisciplinaridade, sendo entendida como ação que permeia diferentes conhecimentos que podem auxiliar no processo de trabalho e no cuidado (MINISTÉRIO DA SAÚDE, 2009).

Essa subcategoria teve uma característica diferente das demais, pois quando os entrevistados foram questionados se já tinham ouvido falar em Apoio Matricial houve uma unanimidade de desconhecimento desta ferramenta, conforme excertos a seguir: "Não, nunca ouvi falar (E1)". "Nunca ouvi. Nunca. (E2)". "Não, esse termo nunca ouvi falar [...] (E3)". "Ah nem... nem sei, infelizmente não sei o significado por si e algo que pode expor também, infelizmente isso não [...] não conheço muito (E4)". "Não, nunca escutei isso (E5)". "Não, não ouvi falar (E6)". "Não, a primeira vez que tô vendo (ouvindo) agora [...] (E7)".

Nesse sentido, corroborando com o que é preconizado pelas regulamentações que regem as Diretrizes do NASF, a formação do profissional de Educação Física necessitaria ir ao encontro desses objetivos. De acordo com as Diretrizes Curriculares Nacionais da graduação em Educação Física, sua formação deveria assegurar:

\begin{abstract}
uma formação generalista, humanista e crítica, qualificadora da intervenção acadêmico-profissional, com rigor científico, na reflexão filosófica e na conduta ética, nesse sentido o profissional deveria estar qualificado para analisar criticamente a realidade social podendo intervir de diferentes formas no que se referem às diferentes manifestações e expressões do movimento humano, com objetivo voltado para a formação, a ampliação e o enriquecimento cultural das pessoas, facilitando assim adoção de um estilo de vida fisicamente ativo e saudável (MINISTÉRIO DA EDUCAÇÃ̄O, 2004).
\end{abstract}

As falas transcritas dos entrevistados corroboram com que Nascimento e Oliveira (2010), em um artigo de revisão, falam sobre a formação do profissional da saúde, que ainda não atende as necessidades do SUS e dificulta o trabalho no NASF. A formação não contempla questões como acolhimento, vínculo, escuta ao próximo e trabalho em equipe, inerentes ao trabalho do NASF. Porém, vale ressaltar que apesar de não declararem conhecer a ferramenta Apoio Matricial, os entrevistados, em outras partes da entrevista sugerem formas de trabalho dentro de uma equipe de saúde interdisciplinar que se aproximam de 
algumas ferramentas que são contempladas nas Diretrizes do NASF, como o Trabalho com Grupos, Projeto Terapêutico Singular, Atendimento Domiciliar Compartilhado, entre outros. Vejamos alguns excertos que podem contribuir com essa argumentação:

\begin{abstract}
Na verdade teria que ser, seria uma cadeia né. Um leva ao outro. A nutricionista leva ao nosso profissional (profissional de Educação Física), o nosso profissional leva ao médico, o médico leva a gente (profissional de Educação Física). A gente leva ao nutricionista, e isso é uma cadeia na verdade. Sempre vai ter que estar unido na verdade (E5).

Assim como na enfermagem, assim como na parte dos fisioterapeutas. Assim eu acho que se tivesse uma equipe com pensadores, cada um de sua área, entrando numa ideia em conjunto, eu acho que com certeza iria acrescentar e muito pra sociedade no geral, melhorar pra população e também com as despesas como já tinha comentado antes na área da saúde né (E6).
\end{abstract}

Ressaltamos os termos e ideias presentes nos excertos "estar unido" em (E5) e "ideia em conjunto" (E6), na medida em que se alinham com o que é preconizado pelas diretrizes nacionais, como por exemplo, o Projeto Terapêutico Singular, que seria uma ferramenta que busca discutir entre as equipes casos específicos e mais complexos em busca de uma prática terapêutica (MINISTÉRIO DA SAÚDE, 2014).

Também houve indicativos de temas referentes ao Apoio Matricial, tais como a aproximação do Trabalho em Grupos, que busca a educação em saúde, a participação social e o empoderamento por parte dos usuários (MINISTÉRIO DA SAÚDE, 2014). Tais elementos se fizeram presentes na entrevista de E2, por exemplo, quando afirma sobre a importância de fazer ações “[...] pelo combate da obesidade, de doenças assim, cardiovasculares, mas assim ele (no caso o profissional de educação física) poderia estar atuando de diversas formas. Fazer um programa, algo trabalhando com os idosos assim".

Além do mais, elementos como a atuação interdisciplinar enquanto ferramentas produtivas de trabalho em saúde foram evidenciadas. Conforme E7, ao se referir ao atendimento do profissional de educação física, este refere que o atendimento "poderia ser também individual. Individual seria mais interessante, pra ser individual teria que ter mais profissionais, e precisa ficar mais tempo no posto de saúde (E7)". Essa reflexão sobre os modos de atendimento também são indicados pelo Ministério da Saúde, que referencia estas ações como Atendimento Individual Compartilhado ou específico, caracterizado como um atendimento para a construção do diagnóstico com o intuito de melhor resolver o problema do usuário (MINISTÉRIO DA SAÚDE, 2009; 2014).

$\mathrm{O}$ atendimento individual pode acontecer de duas formas: a) compartilhado, que seria quando um profissional da equipe de NASF somado a pelo menos mais um profissional da equipe na qual o NASF estaria vinculado, fazem o atendimento ao usuário; b) individual, seria quando somente o profissional da equipe de NASF realiza o atendimento ao usuário. Vale ressaltar que esse atendimento só ocorre após a pactuação entre as equipes de NASF e sua equipe de vínculo, juntamente com um projeto terapêutico construído por ambas as equipes (MINISTÉRIO DA SAÚDE, 2009). 
Através dessa discussão, podemos observar que mesmo os entrevistados não sabendo o que seria especificamente o Apoio Matricial, como assim declararam, em outros pontos das entrevistas relataram situações ou ações de atenção que se aproximam de ferramentas que fazem parte do trabalho do NASF.

\section{CONCLUSÕES}

A formação profissional e universitária no campo da saúde vem sofrendo, ao longo dos últimos anos, uma serie de modificações e redirecionamentos teóricos, práticos e conceituais a fim de atender as demandas e, especialmente, os princípios do SUS. Programas como o Pró-Saúde e as Residências Multiprofissionais, assim como, novas diretrizes curriculares são indicativos desse processo. O Sistema Único de Saúde, que completou 25 anos em 2015, ainda carece de maiores investimentos e, sobretudo, de planificação e organização para melhorar seu funcionamento. No entanto, é imprescindível que os recursos humanos e, em especial, os profissionais e futuros profissionais que lá atuarão estejam em sintonia com os preceitos advogados pela Saúde Coletiva e pela Saúde Pública, enquanto áreas e campos de conhecimento e atuação. Desse modo, urge formações profissionais no ensino superior que apresentem, discutam e atendam os princípios organizadores do SUS, assim como, as estruturas que o compõem, a fim de se realizar uma inserção adequada do perfil profissional que se pretende.

Nesse sentido, a formação superior dos cursos da saúde, e no caso desse estudo da Educação Física, precisam direcionar os estudantes para que melhor compreendam esse cenário de prática, a fim de qualificar sua formação e o trabalho desse futuro profissional. Percebemos nessa pesquisa que os estudantes investigados disseram pouco ou nada conhecer sobre o SUS e as estruturas que organizam seu funcionamento, especialmente a $A B$, o que indica, a partir de excertos de suas falas, que não saberiam como atuar nesse espaço profissional. Tal constatação reverbera não apenas numa inadequação da formação profissional para esse campo, como também e principalmente, corrobora para que o funcionamento dos princípios que norteiam o SUS sejam desqualificados, implicando em maiores dificuldades de avanços na Saúde Pública brasileira por parte dos profissionais recém egressos.

Frente a esses dados, sugere-se que os cursos de formação superior em Educação Física procurem discutir em sua formação os preceitos que regem a Saúde Pública e Coletiva, assim como, os modos pelos quais a profissão da Educação Física pode atuar nesses espaços. Sugere-se, também, continuidade de estudos acerca dessa temática, pois como visto, são poucas as pesquisas que se detenham especificamente nesse tópico. Diante da expansão desse campo de atividade profissional e, sobretudo, pela importância que esse campo ocupa na sociedade brasileira, é preciso novas investigações que contextualizem outras instituições e sujeitos, incluindo até mesmo outros atores sociais que estejam envolvidos nesse processo, assim como, as legislações referentes a essa formação superior. 


\section{REFERÊNCIAS}

BARDIN, Laurence. Análise de conteúdo. São Paulo: Edições 70, 2011.

BATTAGLION, Ângelo. Conhecimento e a prática dos acadêmicos da educação física com atuação na saúde pública. 2003. 145 f. Tese (Doutorado). Escola de Enfermagem de Ribeirão Preto. Universidade de São Paulo. 2003.

BELEl, Renata Aaparecida. et al. O uso de entrevista, observação e videogravação em pesquisa qualitativa. Cadernos de Educação, n. 30, 2008.

CARVALHO, Yara Maria de. Saúde, sociedade e vida: um olhar da Educação Física. Revista Brasileira de Ciências do Esporte, v. 27, n. 3, 2006.

COSTA, Rafael Paula Parreira da. Desvios de verbas do SUS: parâmetros para uma necessária e urgente definição de competência. Revista Eletrônica do Ministério Público do Estado de Goiás, n. 3, p. 319-326, 2012.

CUTOLO, Luigi Agea; CESA, André Inocência. Percepção dos alunos do curso de graduação em medicina da UFSC sobre a concepção saúde/doença das práticas curriculares. Arquivos Catarinenses de Medicina, v. 32, n. 4, p. 75-89, 2003.

DE OLIVEIRA, Lúcio Henrique de; DE MATTOS, Rubem Araújo de; SOUZA, Auta Iselina Stephan. Cidadãos peregrinos: os "usuários" do SUS e os significados de sua demanda a prontos-socorros e hospitais no contexto de um processo de reorientação do modelo assistencial: uma analise a partir de usuários do SUS no município de Juiz de Fora. Ciência \& Saúde Coletiva, v.14, n. 5, p. 1929, 2009.

ESPERIDIÃO, Monique Azevedo; LEAL, Mariana Bertol; FONTOURA, Marília. Gestão compartilhada da formação de profissionais de saúde: reflexões acerca da experiência do curso de especialização em gestão hospitalar para o SUS/Bahia. Revista Baiana de Saúde Pública, v. 33, n. 1, p. 58, 2012.

FERREIRA, Ricardo Corrêa; FIORINI, Vânia Maria Lopes; CRIVELARO, Everton. Formação profissional no SUS: o papel da Atenção Básica em Saúde na perspectiva docente. Revista Brasileira de Educação Médica, v. 34, n. 2, p. 207-15, 2010.

FRAGA, Alex Branco; CARVALHO, Yara Maria; GOMES, Ivan . Políticas de formação em educação física e saúde coletiva. Trabalho, Educação e Saúde (Online), v. 10, p. 367-386, 2012.

FRAGA, Alex Branco; CARVALHO, Yara Maria; GOMES, Ivan (Orgs.) As práticas corporais no campo da saúde. São Paulo, Hucitec, 2013.

FREITAS, Fabiana Fernandes de. A educação física no serviço público de saúde. São Paulo, SP: Hucitec, 2007.

GOMES, Ivan; FRAGA, Alex Branco; CARVALHO, Yara Maria (orgs) Práticas Corporais no Campo da Saúde: uma política em formação [recurso eletrônico] - Porto Alegre: Rede UNIDA, 2015.

GOUVEIA, Roberto; PALMA, José João. SUS: na contramão do neoliberalismo e da exclusão social. Estudos Avançados, v. 13, n. 35, p. 139-146, 1999.

MENDES, Valéria Maria; CARVALHO, Yara Maria de. Práticas corporais e clínica ampliada: experimentando tessituras para a composição de outros modos de cuidado. In WACHS, 
Felipe.; ALMEIDA, Uberson. R.; BRANDÃO, Fabiana Freitas. Educação física e saúde coletiva: cenários, experiências e artefatos culturais. 2016. p. 169-198.

MINISTÉRIO DA EDUCAÇÃO. Conselho Nacional de Educação. Diretrizes para Graduação em Educação Física. Educação Física, 2004. Disponível em: < http://http:// www.confef.org.br/RevistasWeb/n12/04_DIRETRIZES_CURRICULARES.pdf > Acesso em: Nov. 2013.

MINISTÉRIO DA EDUCAÇÃO. Secretaria de Educação Superior. Comissão Nacional de Residência Multiprofissional em Saúde. Resolução n. ${ }^{\circ} 2$ de 13 de Abril de 2012. Dispõe sobre Diretrizes Gerais para os Programas de Residência Multiprofissional e em Profissional de Saúde. Disponível em: < http://www.abmes.org.br/abmes/public/ arquivos/legislacoes/Res-CNRM-002-2012-04-13.pdf > Acesso em: Out. 2015>

MINISTÉRIO DA SAÚDE. Secretaria Nacional de Assistência à Saúde. ABC do SUS: doutrinas e princípios. Brasília, 1990. Disponível em: < http://www.foa.unesp.br/include/ arquivos/foa/pos/files/abc-do-sus-doutrinas-e-principios.pdf > Acesso em: Jun. 2014.

MINISTÉRIO DA SAÚDE. Política Nacional de Humanização. Brasília. 2003. Disponível em:<http://bvsms.saude.gov.br/bvs/publicacoes/politica_nacional_humanizacao_pnh_ folheto.pdf> Acesso em: Out. 2015.

MINISTÉRIO DA SAÚDE. Secretaria de Atenção à Saúde. Departamento de Atenção Básica.

Política Nacional de Atenção Básica. Brasília, 2006. Disponível em: < http://bvsms. saude.gov.br/bvs/publicacoes/politica_nacional_atencao_basica_2006.pdf > Acesso em: Set. 2014

MINISTÉRIO DA SAÚDE. Cadernos de Atenção Básica n. 27. Diretrizes do Nasf: Núcleo de Apoio à Saúde da Família. Brasília, 2009. Disponível em: < http://bvsms.saude.gov.br/ bvs/publicacoes/caderno_atencao_basica_diretrizes_Nasf.pdf > Acesso em: Jun. 2014. MINISTÉRIO DA SAÚDE. Cadernos de Atenção Básica n. 39. Núcleo de Apoio à Saúde da Família - Volume 1: Ferramentas para gestão e para o trabalho cotidiano. Brasília, 2014. Disponível em: < http://bvsms.saude.gov.br/bvs/publicacoes/nucleo_apoio_ saude_familia_cab39.pdf $>$ Acesso em: Jun. 2014.

NASCIMENTO, Débora Dupas Gonçalves do; OLIVEIRA, Maria Amélia De Campos. Reflexões sobre as competências profissionais para o processo de trabalho nos Núcleos de Apoio à Saúde da Família. O Mundo da Saúde, v. 34, n. 1, p. 92-96, 2010.

PALMA, Alexandre. Educação física, corpo e saúde: uma reflexão sobre outros "modos de olhar". Revista Brasileira de Ciências do Esporte, v. 22, n. 2, 2001.

PASQUIM, Heitor Martins. A Saúde Coletiva nos cursos de graduação em Educação Física. Saúde e Sociedade, v. 19, n. 1, p. 193-200, 2010.

POLITELO, Leandro; RIGO, Vitor Paulo; HEIN, Nelson. Eficiência da Aplicação de Recursos no Atendimento do Sistema Único de Saúde (SUS) nas Cidades de Santa Catarina. Revista de Gestão em Sistemas de Saúde, v. 3, n. 2, p. 45-60, 2015.

RAFAELI, Felipe Floriani. PET-saúde da família: contribuições na formação acadêmica e profissional em Educação Física. Trabalho de Conclusão de Curso (Graduação em Educação Física). Universidade Federal de Santa Catarina (UFSC). Florianópolis, 2013. Disponível em: < https://repositorio.ufsc.br/handle/123456789/103745> Acesso em: Jun. 2014. 
SCHRAIBER, Lilia Blima. Pesquisa qualitativa em saúde: reflexões metodológicas do relato oral e produção de narrativas em estudo sobre a profissão médica. Revista de Saúde Pública, São Paulo, v. 29, n. 1, p. 63-74, 1995.

SCHWARTZ, Talita Dourado et al. Estratégia Saúde da Família: avaliando o acesso ao SUS a partir da percepção dos usuários da Unidade de Saúde de Resistência, na região de São Pedro, no município de Vitória (ES). Ciência e saúde coletiva, v. 15, n. 4, p. 2145-2154, 2010.

SILVA, Daysi Jung da; DA ROS, Marco Aurélio. Inserção de profissionais de fisioterapia na equipe de saúde da família e Sistema Único de Saúde: desafios na formação. Ciência e Saúde Coletiva, v. 12, n. 6, p. 1673-81, 2007.

VIEGAS, Selma Maria da Fonseca; PENNA, Cláudia Maria de Mattos. O SUS é universal, mas vivemos de cotas. Revista Ciência \& Saúde Coletiva, v. 18, n. 1, 2013.

WACHS, Felipe; ALMEIDA, Uberson; BRANDÃO, Fabiana Freitas. Educação física e saúde coletiva: cenários, experiências e artefatos culturais. 2016.

Recebido em: setembro/2016

Aprovado em: fevereiro/2017 